\title{
The Impact of Interface Bonding Efficiency on High-Burnup Spent Nuclear Fuel Dynamic Performance
}

\author{
Hao Jiang ${ }^{1}$, Jy-An John Wang, Hong Wang \\ Materials Science and Technology Division \\ Oak Ridge National Laboratory \\ One Bethel Valley Road, Oak Ridge, Tennessee 37831
}

\begin{abstract}
Finite element analysis (FEA) was used to investigate the impact of interfacial bonding efficiency at pellet-pellet and pellet-clad interfaces of high-burnup (HBU) spent nuclear fuel (SNF) on system dynamic performance. Bending moments $\mathrm{M}$ were applied to FEA model to evaluate the system responses. From bending curvature, $\kappa$, flexural rigidity EI can be estimated as $E I=M / \kappa$. The FEA simulation results were benchmarked with experimental results from cyclic integrated reversal bending fatigue test (CIRFT) of HBR fuel rods. The consequence of interface debonding between fuel pellets and cladding is a redistribution of the loads carried by the fuel pellets to the clad, which results in a reduction in composite rod system flexural rigidity. Therefore, the interface bonding efficiency at the pellet-pellet and pellet-clad interfaces can significantly dictate the SNF system dynamic performance. With the consideration of interface bonding efficiency, the HBU SNF fuel property was estimated with CIRFT test data.
\end{abstract}

Key words: Spent nuclear fuel, interface bonding, dynamic performance

\section{INTRODUCTION AND BACKGROUND}

The research discussed in this paper was conducted to support the Department of Energy (DOE) Used Fuel Disposition Campaign (UFDC) modeling, simulation, and experiment integration research, development, and deployment plan for spent nuclear fuel (SNF) integrity and structural performance under normal conditions of transportation [1]. In high-burnup (HBU) SNF, the fuel pellets and clad are normally fused together by chemical and mechanical interactions to form an integrated SNF system; or the pellets and clad are compressed together by radial residual stresses resulting from the mechanical interaction of the pellets and clad. To understand the underlying mechanisms of pellet-pellet and pelletclad interface dynamics in a transportation environment, it is essential to accurately evaluate the mechanical properties of the integrated SNF system.

The Oak Ridge National Laboratory (ORNL) has developed the cyclic integrated reversible-bending fatigue tester (CIRFT) to successfully demonstrate controllable fatigue fracturing of HBU SNF in a normal vibration mode [2-4]. CIRFT enables examination of the underlying mechanisms of the dynamic performance of the SNF system. The major findings regarding CIRFT for HBU SNF are as follows:

- SNF system interface bonding plays an important role in SNF vibration performance.

${ }^{1}$ Corresponding author, Tel: 1-865-574-5712; Fax: 1-865-574-6098; email: jiangh@ornl.gov

Notice: This manuscript has been authored by UT-Battelle, LLC under Contract No. DE-AC05-00OR22725 with the U.S. Department of Energy. The United States Government retains and the publisher, by accepting the article for publication, acknowledges that the United States Government retains a non-exclusive, paid-up, irrevocable, worldwide license to publish or reproduce the published form of this manuscript, or allow others to do so, for United States Government purposes. The Department of Energy will provide public access to these results of federally sponsored research in accordance with the DOE Public Access Plan (http://energy.gov/downloads/doe-publicaccess-plan). 
- Fuel structure contributes to SNF system stiffness.

- There are significant variations in the stress and curvature of SNF systems during vibration cycles resulting from segment pellet and clad interactions.

- SNF failure initiates at the pellet-pellet interface region and appears to be spontaneous.

Because of the inhomogeneous composite structure of the SNF system, finite element analysis (FEA) is needed to translate global moment-curvature measurements into local stress-strain profiles for further investigation. Furthermore, the detailed mechanisms of the pellet-pellet and pellet-clad interactions and the stress concentration effects at the pellet-pellet interface cannot be readily obtained from a CIRFT system measurement. Therefore, detailed FEA is necessary to obtain further interpretation of SNF stressstrain profiles from the global test response.

This study provides detailed explanations of the effects of pellet-pellet and pellet-clad interactionsincluding pellet fracture and pellet-clad bonding efficiency - on the clad structural performance under pure bending during normal transportation. The FEA model of an H. B. Robinson (HBR) fuel rod system is formed by considering HBR pellets and Zircaloy-4 (Zr-4) cladding, including bonding at clad/pellet interfaces and the fuel system boundary conditions.

Uranium dioxide $\left(\mathrm{UO}_{2}\right)$ fuel pellet properties have been investigated extensively in nuclear industry and research. Stehle et.al [5] provided comprehensive review of $\mathrm{UO}_{2}$ properties for LWR fuel rods in 1975. Radford [6] studied the effect of fabrication parameters and microstructures on the mechanical strength of $\mathrm{UO}_{2}$ fuel pellets. Michel et.al $[7,8]$ worked on a new phenomenological criterion for pelletcladding interaction rupture. From their study 3D fuel cracking modelling in pellet cladding mechanical interaction under reactor operation was conducted to understand the effect of pellet mechanical properties on cladding local loading. The research concluded that pellet cracking tends to reduce tangential stress at pellet-cladding interface due to a loss of stiffness of the pellet fragment. Hence the risk of pellet-cladding interaction failure was significantly reduced when the fuel tensile strength was divided by two in their modeling.

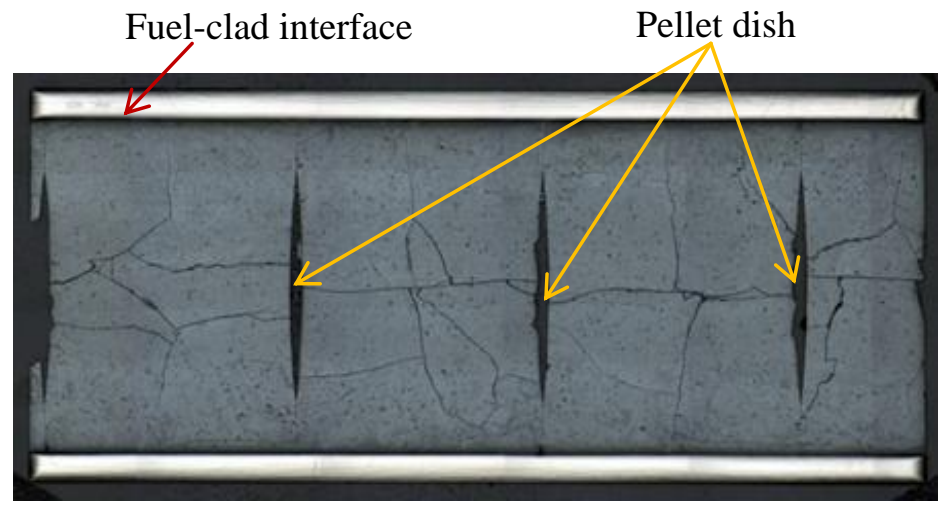

Figure 1. PWR high-burnup SNF rod used for CIRFT testing reveals good bonding at fuel-clad interface.

In HBR high burn-up SNF as shown in Figure 1, even with cracks in the pellets, the radial compressive residual stress within clad, in addition to the chemical bond at pellet-clad interface, confines the cracking pellets to form one integrated system. Thus, in the study fuel pellet cracking was not considered in FEA simulation, however cracking phenomenon was considered in HBU fuel property estimate. To assess the fuel cladding performance, the fuel pellets of $\mathrm{UO}_{2}$ material in this study was assumed to possess tensile strength cited from ref.[9].

Geelhood et al. in Pacific Northwest National Laboratory has done comprehensive study on cladding material of Zircaloy and Zr-4 mechanical properties data was published in report PNNL-17700[10]. Baseline $\mathrm{Zr}-4$ cladding has anisotropic material characteristic, however, in general practice for the irradiated Zr-4 cladding, Zr-4 clad was assumed to be isotropic as stated in PNNL-17700[10]. 
Marchal et al. [11] performed finite element simulation of pellet-cladding interaction in nuclear fuel rods under power ramp test condition. Results showed that pellet-clad friction played important role on the influence of the fuel mechanical properties. In this study, in addition to the pellet-clad friction, an interface bonding was modeled to simulate complex chemical adhesive bonding or compressive residual stress for the high burn-up SNF.

The model consists of a fuel rod with a 3-dimensional representation of fuel pellets, clad, and the combinations of potential gaps at the pellet-pellet and pellet-clad interfaces. The ABAQUS code was used, and the fuel rod was represented by a beam element with the associated effective stiffness. This approach was used to obtain effective properties data for the beam elements as input for further development of the detailed SNF assembly model. This pellet-clad interaction modeling uses a "contact element" algorithm and can be further implemented into other embedded boundary conditions, such as internal pressure and residual stress. The FEA simulation results were also calibrated and benchmarked with data $[12,13]$ obtained from ORNL reversal bending fatigue testing.

The objective of this research is to use the developed FEA protocols to understand and estimate interface bonding efficiency of a SNF system, as well as to study the potential impact of interface bonding efficiency on SNF structural performance under the normal conditions of transport (NCT). FEA was also used to translate the global response of CIRFT examination to the local stress-strain level and to quantify the CIRFT system biases and associated uncertainties for the HBU SNF being tested, as well as to provide reasonable estimation of HBU fuel property. This paper provides the FEA methodology used to evaluate the effects of pellet-pellet and pellet-clad interactions.

\section{CIRFT TESTING}

Figure 2 shows CIRFT testing system with horizontal U-frame test setup [2-4]. Push-pull forces of linear motors translated to bending moment on the fuel rod sample. There were three LVDT at 2 inch gauge section of the fuel rod to measure three points of deflections on the clad outside wall. Based on the measured deflections, the curvature of the fuel rod under bending was calculated. In the hot-cell environment, the measurements are usually limited. For the CIRTF testing, the measurements we can get are moment and curvature.

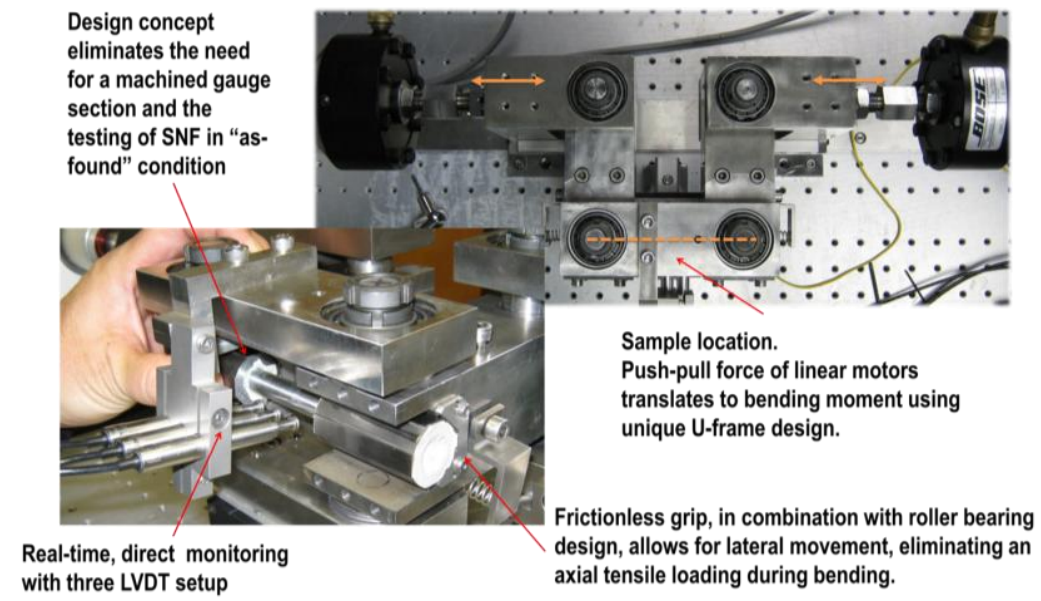

Figure 2.CIRFT testing system with horizontal U-frame test setup.

Furthermore, the flexural rigidity $E I$ (the product of the Young's modulus $E$ and the moment of inertia $I$ ) of a fuel rod can be estimated using the applied moment $M$ and the resultant curvature, $\kappa$, as described in Eq. (1).

$$
E I=M / \kappa
$$


The flexural rigidity EI was chosen as main parameter to evaluate fuel rod system in CIRFT testing. Figure 3 shows ORNL hot-cell CIRFT test data of HBR high burn-up SNF. In this testing, the bending moment applied on HBR high burn-up SNF sample was set to $6.25 \mathrm{Nm}$. From induced curvature in Figure 3 (right), the flexural rigidity estimated from Eq.(1) under the cyclic loading was shown in Figure 3 (left).
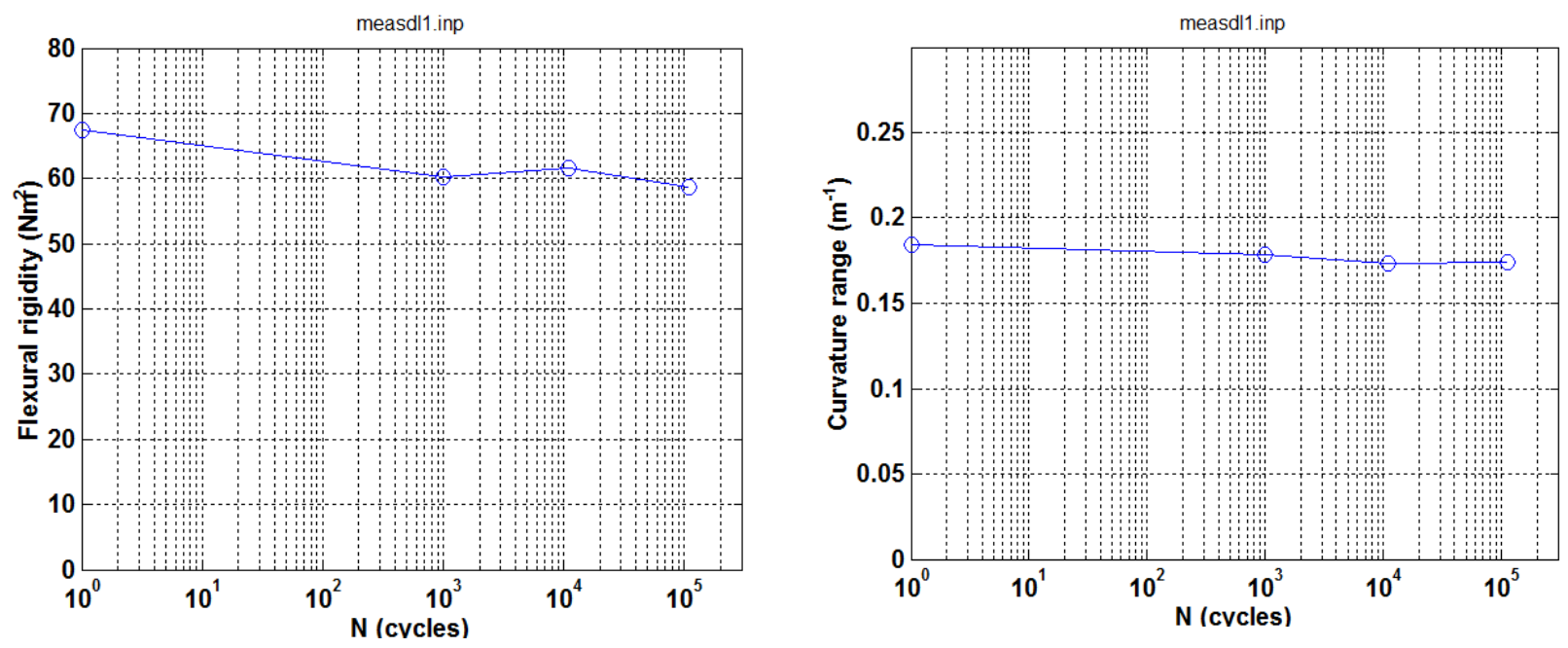

Figure 3. ORNL hot-cell CIRFT test data, (Left) flexural rigidity and (Right) curvature [3].

\section{INTERFACE BONDING ANALYSIS OF FUEL ROD WITH HBR PELLETS}

To understand the CIRFT test data and the mechanisms behind the change in the flexural rigidity under the cyclic loading, the FEA models with 2-inch gauge section that covers the Zr-4 clad and HBR pellets, as well as interfacial layers that served as cohesive bonding or radial compressive residual stress from pellet clad contact pressure, were developed using the ABAQUS code. In order to estimate the fuel rod system responses including the stress profile and the associated curvature, $\kappa$, the bending moments (M) were applied to both ends of the fuel rod. To benchmark with CIRFT test data in Figure 3, the applied bending moment was the same as the testing $6.25 \mathrm{Nm}$. The flexural rigidity (EI) of the FEA simulation cases were estimated by using Eq.(1).

Five generalized interface bonding conditions were simulated, which provided the fundamental understanding on the interface bonding efficiency for HBU SNF composite system. However, in reality it was much more complex system regarding interface bonding conditions within a HBU SNF specimens. The detailed discussions of the simulation cases are divided into the following sections.

- Effect of bonding material with good interface bonding

- Effect of interface debonding

$>$ Debonded pellet-pellet interfaces with empty gaps

$>$ Debonded pellet-clad and pellet-pellet interfaces with empty gaps

- Effect of gaps between pellets

$>$ Debonded pellet-pellet interfaces without gaps

$>$ Debonded pellet-clad and pellet-pellet interfaces without gaps 


\subsection{INTERFACE BONDING MODELS}

ABAQUS was used for a structural analysis and interfacial bonding evaluation of fuel rods with HBR pellets. The rods were tested in a hot-cell environment in the CIRFT developed by ORNL [2-4]. To validate the simulation results, the same fuel rod materials were used in the hot-cell tests and the FEA. The HBR pellet material was $\mathrm{UO}_{2}$. In the simulations, the fresh fuel property was used without aging consideration. The clad material was $\mathrm{Zr}-4$. An interface bonding material to simulate fused areas used the elastic properties of epoxy. Table 1 lists the material properties of the fuel rod.

Table 1. Mechanical properties of the fuel rod

\begin{tabular}{|c|c|c|c|c|}
\hline Material & $\begin{array}{c}\text { Young's modulus } \\
(\mathrm{GPa})\end{array}$ & Poisson's ratio & $\begin{array}{c}\text { Yield strength } \\
(\mathrm{MPa})\end{array}$ & $\begin{array}{c}\text { Density } \\
\left(\mathrm{kg} / \mathrm{m}^{3}\right)\end{array}$ \\
\hline $\mathrm{UO}_{2}{ }^{a}$ & 201 & 0.32 & $2146^{\mathrm{b}}$ & 10970 \\
\hline Zircaloy-4 $^{c}$ & 91 & 0.33 & 906 & 6560 \\
\hline Epoxy $^{d}$ & 3.5 & 0.37 & 69 & 1251 \\
\hline
\end{tabular}

${ }^{a}$ Ref. [9], ${ }^{b}$ Tensile strength, ${ }^{c}$ Ref.[10], ${ }^{d}$ Ref. [2]

A finite element model was established to represent the $50.8 \mathrm{~mm}$ gauge section of the test specimen. Figure 1 shows a 1 in. HBR rod segment from a hot-cell testing sample. The measured outer diameter (OD) of the clad is $10.795 \mathrm{~mm}$. The cladding thickness is $0.787 \mathrm{~mm}$, so the inner diameter (ID) is 9.246 $\mathrm{mm}$. Figure 1gives a clear view of the HBR pellets. The pellet length is $6.916 \mathrm{~mm}$. The pellet ends dish in to reduce pellet surface clinging (Figure 1). The pellet OD is $8.992 \mathrm{~mm}$. An HBR pellet was modeled by FEA to represent the real testing sample. Both ends of the pellet were constructed with a dip diameter of $6.35 \mathrm{~mm}$ and a depth of $0.0152 \mathrm{~mm}$, so that the end surfaces would not touch at the dished-in areas. Thin layers with elastic properties of epoxy were to simulate adhesive bonding or radial compressive residual stress. The thickness of the epoxy layer was $0.127 \mathrm{~mm}$ at the pellet-clad interface and $0.0356 \mathrm{~mm}$ at the pellet-pellet interface.

Figure 4 illustrates the $50.8 \mathrm{~mm}$ gauge section model with HBR pellets, in which there are six fulllength and two partial-length pellets. Bending moments were applied on both ends of the fuel rod rotating along the $X$ axis as shown in Figure 4 (b). To validate the FEA simulation with hot-cell testing data, the bending moment $\mathrm{M}_{\mathrm{x}}$ was the same as that used in the CIRFT tests, $6.25 \mathrm{~N} \cdot \mathrm{m}$. Both loading surfaces of the HBR fuel rod were constrained with rotation along the $Y$ and $Z$ axes and translation along the $X$ direction. In the following finite element models, the global mesh was $0.508 \mathrm{~mm}$ and some local meshes were as small as $0.0635 \mathrm{~mm}$. The quasi-static procedure from ABAQUS was used in the FEA.

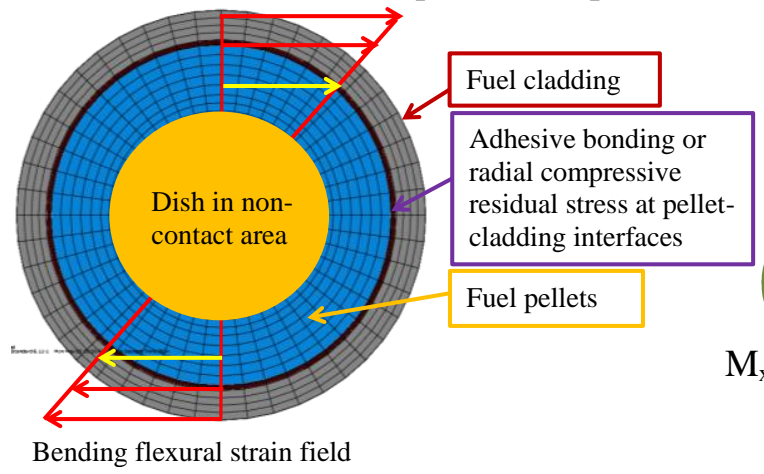

(a)

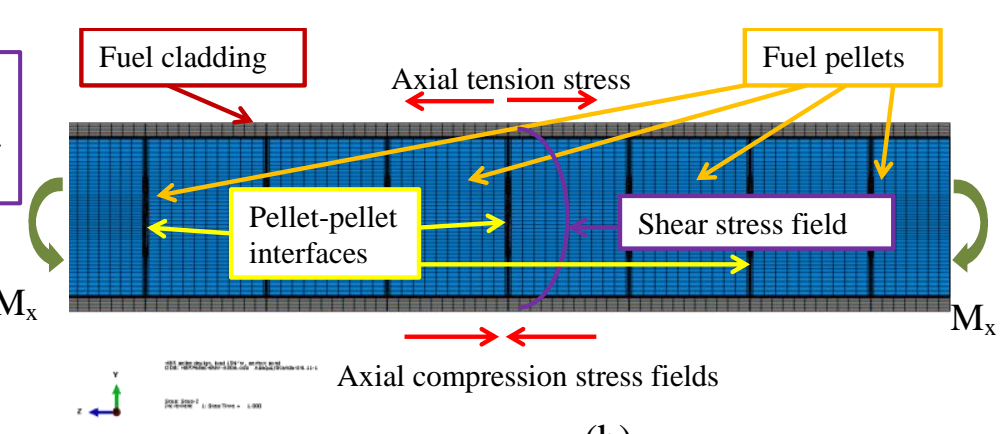

(b)

Figure 4. Geometry of $50.8 \mathrm{~mm}$ section SNF model with eight HBR pellets and associated vibrationinduced bending stress fields. 
The interfacial bonding material was assumed to retain the elastic properties of epoxy. The impact of the interfacial material on bonding efficiency was qualitatively investigated by changing the Young's modulus of the interfacial material to 10 times that of epoxy. This will be discussed in section 4 of this paper.

\subsection{EFFECT OF BONDING MATERIAL WITH GOOD INTERFACE BONDING}

To simulate good interface bonding at the pellet-pellet interface and an unfractured rod system, the pellet-pellet and pellet-clad interfaces were all tied with interface layers. The resulting normal stress distribution under the bending moment of $6.25 \mathrm{~N} \cdot \mathrm{m}$ is shown in Figure 5. It was found that the maximum stress occurred at the pellets, which indicates that the perfectly bonded HBR pellets carry a larger portion of the moment resistance than does the clad. Based on the detailed view of the zoom-in area in Figure 5(b), the location of the maximum stress was at the tie area at the pellet-pellet interface. The perfect bond assigned at the interface tie area was carrying most of the bending moment resistance. The stress in the clad was lower than its yield value of $906 \mathrm{MPa}$. So the clad did not yield under the $6.25 \mathrm{~N} \cdot \mathrm{m}$ bending moment, nor did the HBR pellet. This indicates that the HBR fuel rod with a perfect bonding condition will exhibit linear elastic behavior under the target loading.

The resultant $\sigma_{\mathrm{zz}}$ at the pellet-pellet interface in Figure 5(c) shows that the maximum stress is concentrated on the limited tie areas. This occurred because the dips in the ends of the pellets caused the contact surfaces to be confined to a limited area.

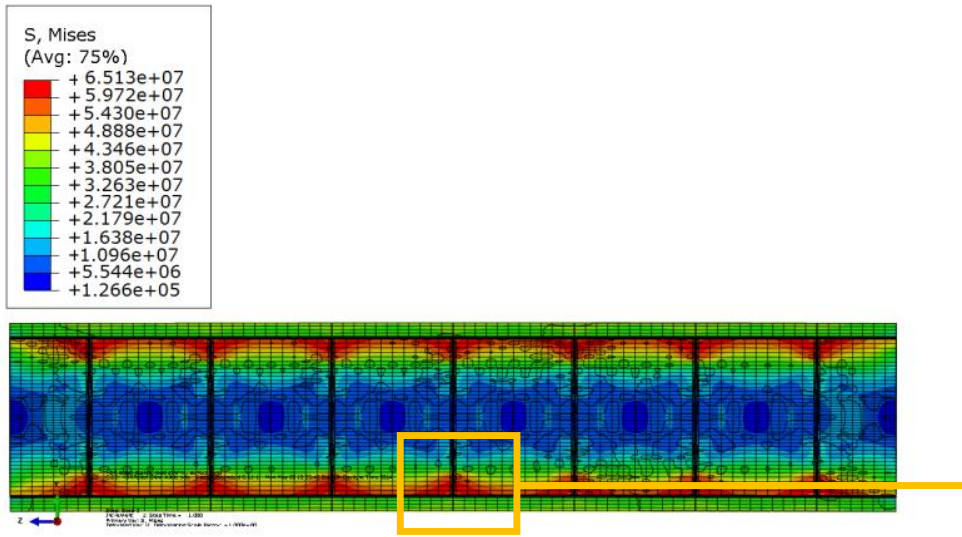

(a) Longitudinal view of the von Mises stress distributions

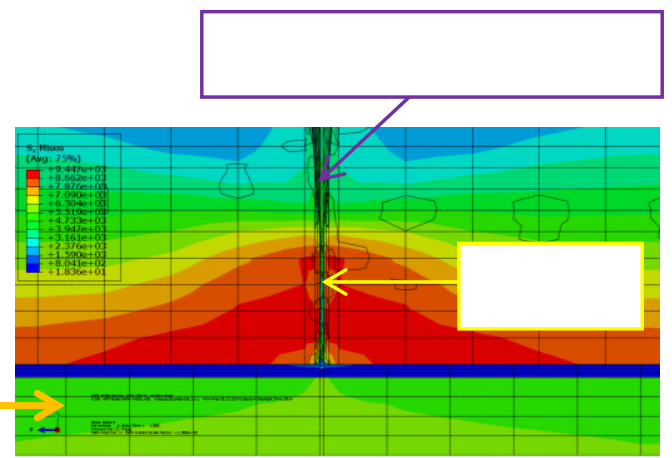

(b) Detailed view in the zoom-in area

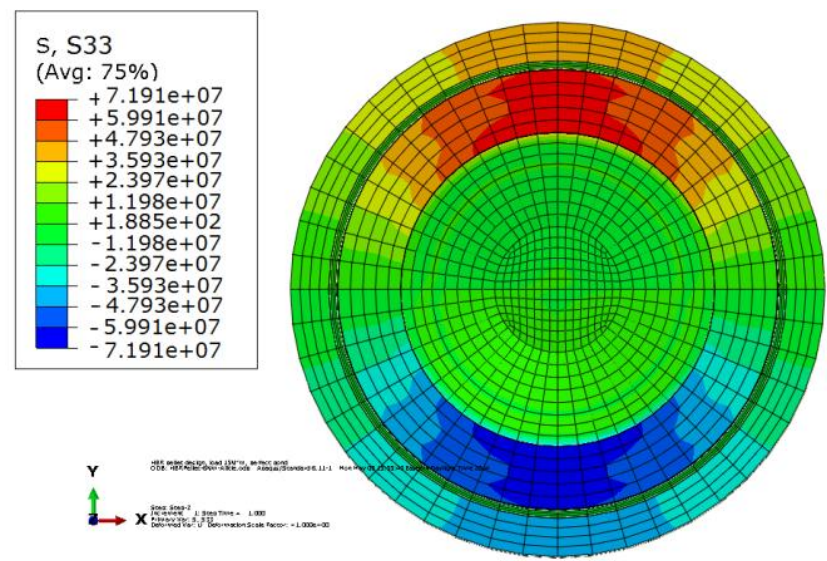

(c) Cross section view of $\sigma_{\mathrm{zz}}$ at a pellet-pellet interface 
Figure 5. Normal stress distribution and curvature results for $50.8 \mathrm{~mm}$ gauge section model of HBR pellets with perfect bonding.

Figure 6 shows the shear stress distribution under the bending moment of $6.25 \mathrm{~N} \cdot \mathrm{m}$ at the cladding. Shear stresses at the cladding were small. As a result of the perfect bonding, the pellets and the cladding responded as a single structure. There was no shear stress concentration inside the gauge section. The stress concentration occurred at the boundary as a result of a composite material mismatch under flexural deformation.

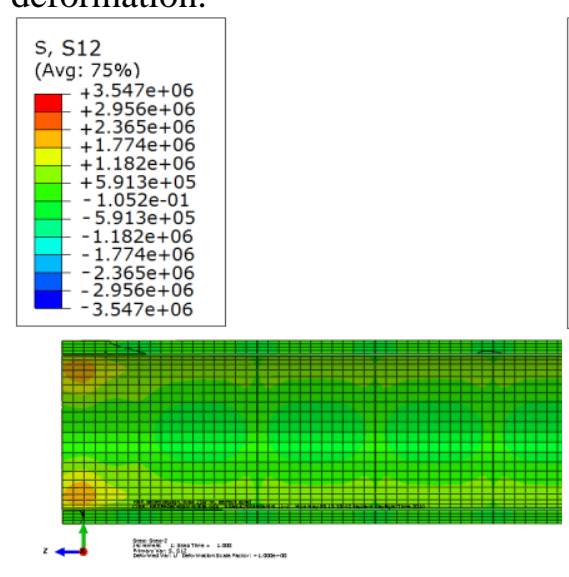

(a) Shear stress $\sigma_{x y}$
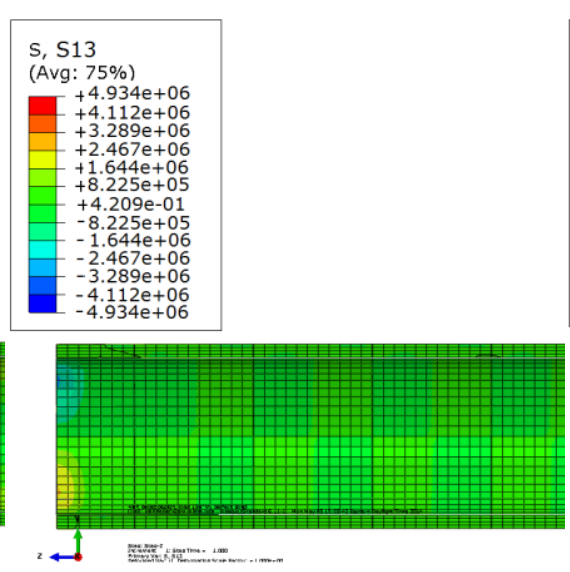

(b) Shear stress $\sigma_{\mathrm{xz}}$

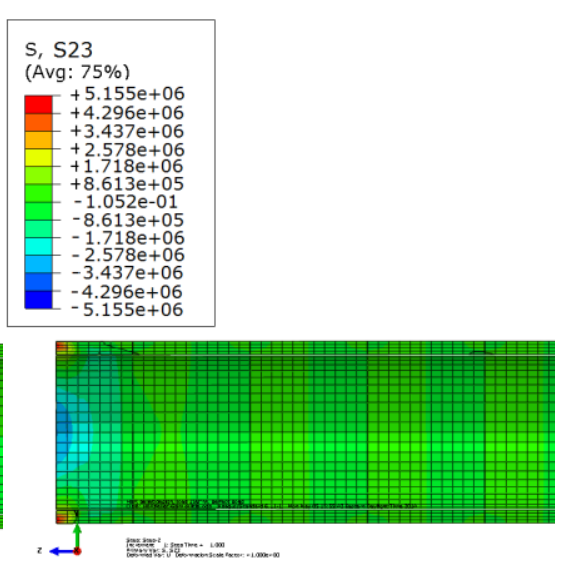

(c) Shear stress $\sigma_{\mathrm{yz}}$

Figure 6. Shear stress distribution at the clad for the $50.8 \mathrm{~mm}$ gauge section model of pellets with perfect bonding.

The bending moment $M$ was applied to both ends of the fuel rod, and the bending curvature $\kappa$ was estimated from the FEA results within the gauge section. The fuel rod bending curvature was derived from the clad deflection data. The curvature $\kappa$ can be defined by the radius of circle R. Three deflection data points at the clad outside wall can be used to determine the radius of circle $\mathrm{R}$ in Figure 7, as follows:

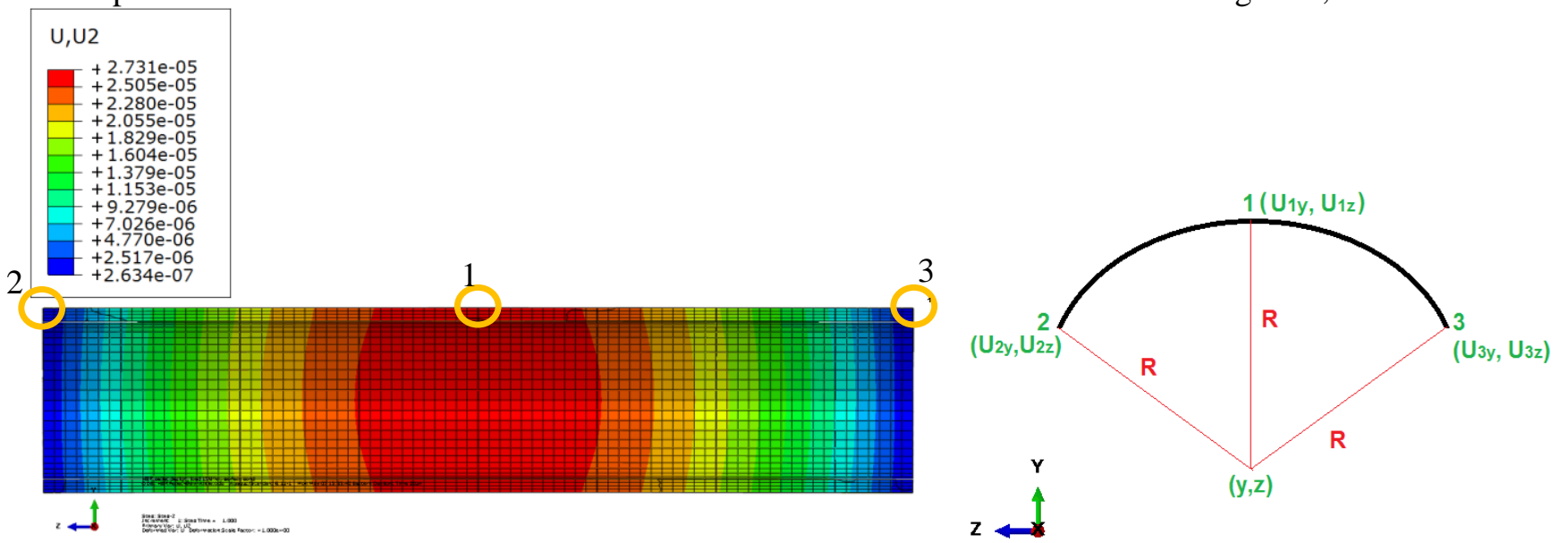

Figure 7. Three deflection data points at the clad outside wall and sketch for curvature calculation.

So the radius of circle $\mathrm{R}$ is

$R=\sqrt{\left(U_{1 y}-y\right)^{2}+\left(U_{1 z}-z\right)^{2}}=\sqrt{\left(U_{2 y}-y\right)^{2}+\left(U_{2 z}-z\right)^{2}}=\sqrt{\left(U_{1 y}-y\right)^{2}+\left(U_{2 z}-z\right)^{2}}$

The curvature $\kappa$ can be determined as 


$$
\kappa=\frac{1}{R}
$$

The resultant curvature was $0.082 \mathrm{~m}^{-1}$. Furthermore, the flexural rigidity $E I$ (the product of the Young's modulus $E$ and the moment of inertia $I$ ) of a fuel rod can be estimated using the applied moment $M$ and the resultant curvature, $\kappa$, as described in Eq. (1).

The flexure rigidity for a perfect bonding condition with epoxy as the adhesive bonding material was $77 \mathrm{~N} \cdot \mathrm{m}^{2}$ for the HBR pellet fuel rod. Based on the resulting $\sigma_{\mathrm{zz}}$, as shown in Figure 5(c), the estimated bending moments for the cladding and pellets were $2.45 \mathrm{~N} \cdot \mathrm{m}$ and $3.8 \mathrm{~N} \cdot \mathrm{m}$, respectively. The total resultant bending moment was equal to the bending load $M_{x}$, of $6.25 \mathrm{~N} \cdot \mathrm{m}$. Based on load-carrying capacity, the perfectly bonded pellets carried more bending moment than the cladding. With perfect interface bonding and without fuel rod fracture, the fuel pellets can carry most of the bending moment under NCT as a result of the higher Young's modulus of the fuel pellet compared with the clad and higher tensile strength, as shown in Table 1.

Typically, the HBU SNF system interfaces bonding is good or remains intact as revealed from high flexural rigidity obtained from the static CIRFT test data. Thus, the static CIRFT test data was used to benchmark the FEA simulation result of perfect bonding case. The CIRFT test data also show that soon after the first fatigue cycle completed, the flexural rigidity of CIRFT test data was decreased compared to that of static CIRFT test; with continuing fatigue cycling, the flexural rigidity data remain stable till the fatigue fracture occurred. This phase of decreased flexural rigidity phenomenon was characterized as the result of the pellet-pellet interface debonding effect.

\subsection{EFFECT OF INTERFACE DEBONDING}

Even before HBU SNF is transported, there are inherent residual stress fields in the SNF system due to reactor operation. For example, there would be axial tensile stress and tangential tensile stress due to pellet-clad mechanical interaction or oxide volume expansion, radial compressive stress due to hydride compaction, and tangential shear stress due to hydride volume expansion. Vibration during transportation will induce reversal bending in the SNF assembly. Repeated expansion and contraction in both the axial and tangential directions of the SNF rod due to reversal bending flexural deformation, combined with stress concentration, can degrade the interface bonding at the fuel pellet-clad and pellet-pellet interfaces (Figure 4). Although the shear stress is small relative to the normal stress due to bending, that does not mean that it can be neglected. In composite rods or SNF rods, in particular, excessive shear due to material mismatch can be a cause of interfacial bonding failure under cyclic loadings.

At pellet-pellet interfaces, interfacial bonding failure is caused mostly by normal stress due to reversal bending flexural deformation combined with relatively smaller shear stress (see Figure 4[b]). At pelletclad interfaces, localized high shear stress will also arise to compensate for the material mismatch under flexural deformation. As mentioned earlier, the shear stress is small relative to the normal stress; therefore, it is likely that interfacial bonding failure at pellet-pellet interfaces will begin before debonding at pellet-clad interfaces occurs. In addition, the HBR pellets have dished noncontact areas at the edges, so the bonding area at the pellet-pellet interface is limited to a relatively small area. That would make it easier for the pellet-pellet interfaces to debond. Observations from an ORNL reversal bending fatigue surrogate stainless steel rod with alumina pellets verified this hypothesis. All the rods fractured right at the pellet-pellet interfaces.

In this section, the same $50.8 \mathrm{~mm}$ gauge section model with eight pellets under $6.25 \mathrm{~N} \cdot \mathrm{m}$ bending moment is used to investigate the HBR fuel rod bending response with interface debonding. The simulation started with a good adhesive bonding at pellet-clad interfaces and debonding at pellet-pellet interfaces. The debonding at pellet-pellet or pellet-clad interfaces uses contact algorithm. 


\subsubsection{Debonded pellet-pellet interfaces with empty gaps}

To simulate a good Adhesive bond condition or radial compressive residual stress at pellet-clad interfaces, a thin epoxy layer was tied to the surfaces at the pellet-clad interfaces. In this section, the case study was designed to simulate the response with a debonded pellet-pellet interface. There were empty gaps at the pellet-pellet interfaces. During bending flexural deformation, the pellets overcame the gaps and then contacted one another at the interfaces.

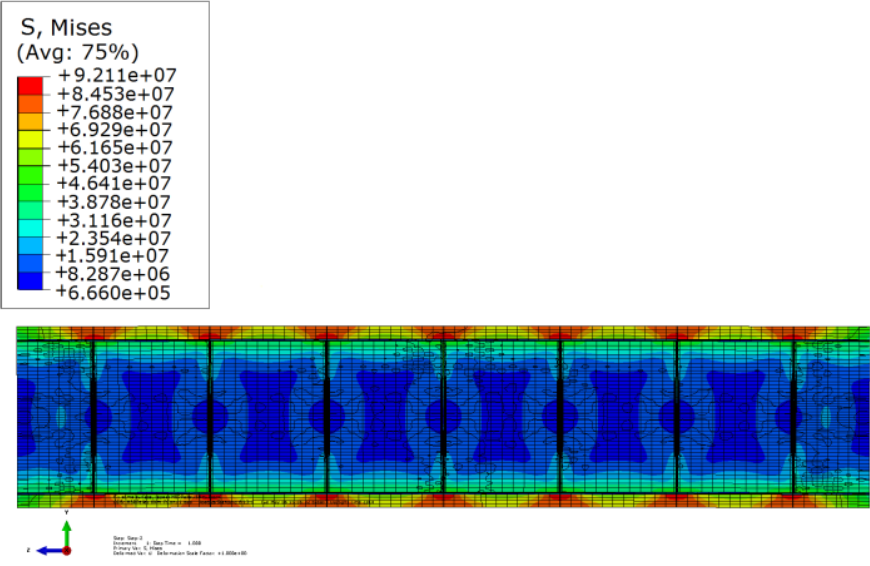

(a) Longitudinal view of resultant von Mises stress

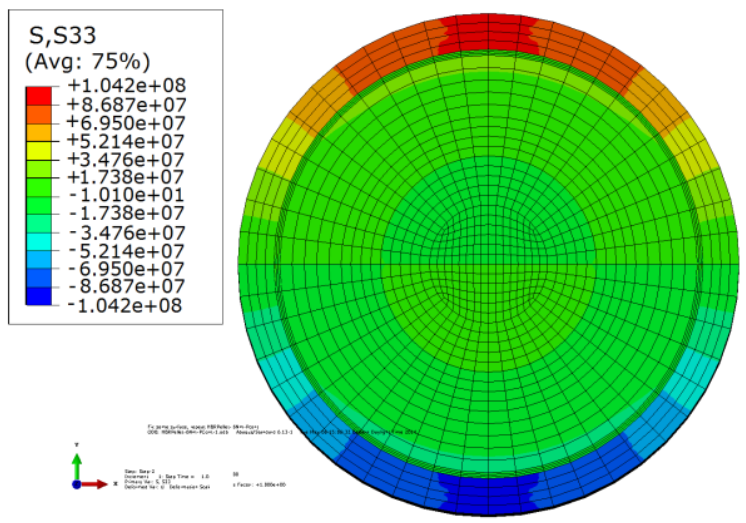

(b) Cross section view of resultant $\sigma_{z z}$ at a pellet-pellet interface

Figure 8. Normal stress distribution results for $50.8 \mathrm{~mm}$ gauge section model of HBR pellets with debonded pellet-pellet interfaces with gaps, and bonded pellet-clad interfaces.

The normal stress responses to the bending moment are illustrated in Figure 8. Compared with the results shown in Figure 5, there were significant differences in the stress distribution between the pelletpellet interface bonding case and the pellet-pellet interface debonding case; the pellet-clad interface remained perfectly bonded in both cases. For instance, in Figure 5, the results of the perfect bond case show that the pellets carry significant bending moment resistance and the maximum stress resides on the pellets. At the pellet-pellet interface in the debonding case, the maximum stress occurred at the clad and was located at the top and bottom portions of the pellet-pellet interface regions. At the debonded pelletpellet interfaces, the pellets can transfer load only via hard contact, so the load-carrying capacity shifts significantly from the pellets to the clad. When the Zr-4 clad starts to carry most of the bending moment at the pellet-pellet interface region, the result is maximum stress concentration at the $\mathrm{Zr}-4 \mathrm{clad}$. However, as a result of the small bending moment, the maximum stress at the clad was 10 times lower than the yield strength of $\mathrm{Zr}-4$, as shown in Table 1, so the $\mathrm{Zr}-4$ clad did not yield. In most of the clad, the stress was much lower than the maximum because the perfect pellet-clad bonding provided good support to the clad. Since there were gaps between pellet-pellet interfaces, the clad deformed continuously until the gaps were reduced by direct contact of the pellet-pellet surfaces. No stress concentration was observed at the pelletpellet contact corners, though. Based on the resulting $\sigma_{z z}$, as shown in Figure 8, the bending moment was calculated for the cladding and pellets, as $5.73 \mathrm{~N} \cdot \mathrm{m}$ and $0.52 \mathrm{~N} \cdot \mathrm{m}$, respectively. The bending moments clearly indicate that the clad takes over more of the bending moment resistance than the pellets at the debonded pellet-pellet interfaces.

There was large discrepancy between the cases for the induced curvature. In the debonding case, the curvature is $0.16 \mathrm{~m}^{-1}$, double that of the perfect bond case of curvature $0.082 \mathrm{~m}^{-1}$. The estimated flexural rigidity of $39 \mathrm{~N} \cdot \mathrm{m}^{2}$ for the case of a debonded pellet-pellet interface is a reduction of about $49 \%$, compared with $77 \mathrm{~N} \cdot \mathrm{m}^{2}$ for perfect interfacial bonding. 
In Figure 9, the difference from the results in Figure 6 for the perfect bond case is apparent. With the pellet-pellet interfaces debonded, the shear stresses surged near the pellet-pellet interface debonding region inside the cladding. The reason might be an increase in shear stress due to a composite material mismatch at the debonded pellet-pellet interface boundary under bending flexural deformation. With good adhesive bonding at pellet-clad interfaces, the clad transferred some shear load at the debonding region. If there are small gaps at the pellet-pellet interfaces, the shear stress concentration occurs at both the top tension and the bottom compression regions of the clad. Maximum stress levels were higher than in perfect bond cases; however, the shear stresses were still one order of magnitude lower than the normal stress in the same simulation case.

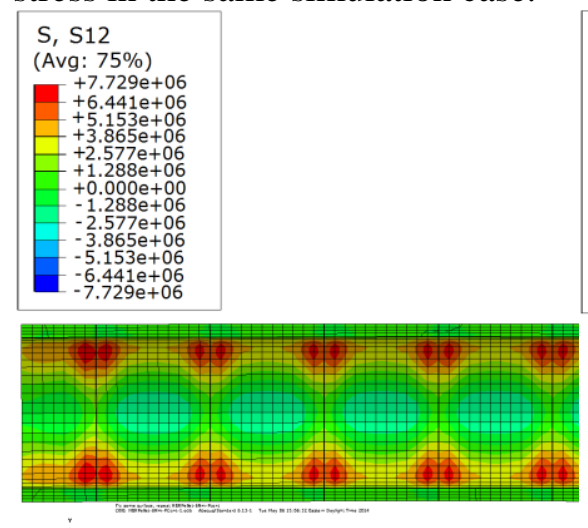

ـ

(a) Shear stress $\sigma_{x y}$
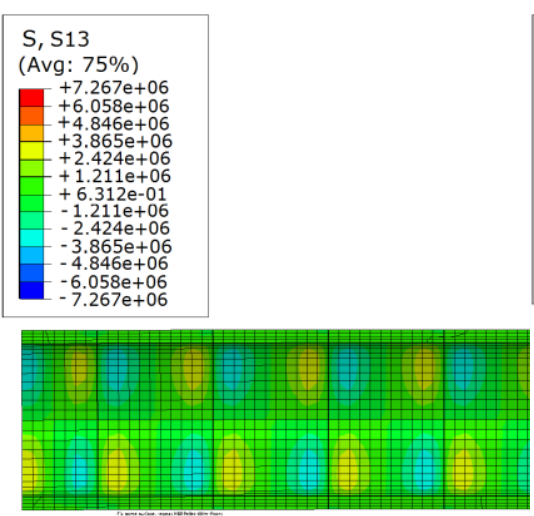

$\leftrightarrow$

(b) Shear stress $\sigma_{\mathrm{xz}}$
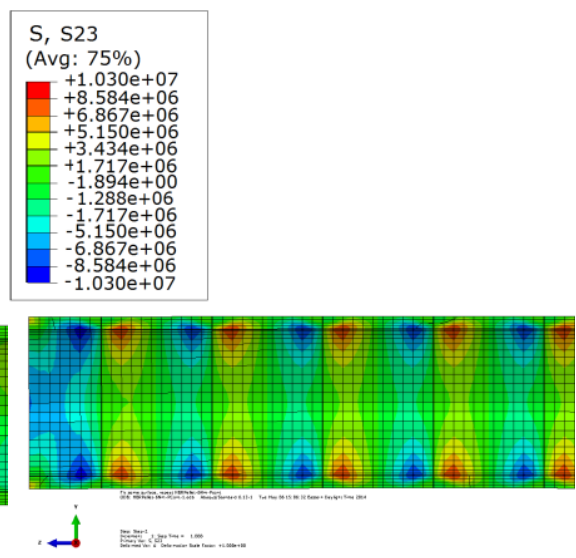

(c) Shear stress $\sigma_{\mathrm{yz}}$

Figure 9.Shear stress distribution at the clad of the $50.8 \mathrm{~mm}$ gauge section model of $\mathrm{HBR}$ pellets with debonded pellet-pellet interfaces with gaps, and bonded pellet-clad interfaces.

\subsubsection{Debonded pellet-clad and pellet-pellet interfaces with empty gaps}

Under flexural deformation, high shear stress will arise at the pellet-clad interfaces to compensate for the material mismatch, in addition to the flexural shear stress in the SNF system. Thus under reversal bending loading during normal transportation, both cyclic normal stress and shear stress can further degrade the interface bonding at pellet-clad interfaces. In this section, the case study was designed to simulate the response with both debonded pellet-clad and pellet-pellet interfaces. A thin layer of bonding material with elastic properties of epoxy was filled at debonded pellet-clad interfaces. There were also empty gaps at the pellet-pellet interfaces.

The resulting normal stress distribution shown in Figure 10 indicates that the clad reached maximum stress throughout the whole gauge section when interfacial debonding occurred at both pellet-clad and pellet-pellet interfaces. This result is in strong contrast to the results in Figure 8, where the $\mathrm{Zr}-4 \mathrm{clad}$ shows stress concentrations only locally at pellet-pellet interface regions. It suggests that, as a result of the interface debonding at both the pellet-clad and pellet-pellet interfaces, the pellets and the clad can contact (or pin) only at the pellet-pellet-clad interface region, and pellets cannot provide direct internal support to the clad. Therefore, the load-carrying capacity shifts significantly from pellets to the clad in the entire gauge section. The bending moment estimated form resultant $\sigma_{\mathrm{zz}}$ in Figure 10 in clad was $6.23 \mathrm{~N} \cdot \mathrm{m}$ and that in pellet was $0.02 \mathrm{~N} \cdot \mathrm{m}$. The results indicate that the $\mathrm{Zr}-4$ clad for pellet-clad and pellet-pellet interfaces both debonding case carries more bending moment resistance than the $\mathrm{Zr}-4$ clad did for only pellet-pellet interfaces debonding case. This means more shift in bending moment resistance from the pellets to the clad as a result of further debonding at pellet-cald interfaces. However, the clad did not yield at the maximum stress, because of the small bending load and high material yield strength. The pellets were all below the yielding stress as well. The bending deformation in the debonded pellet-clad region is 
likely to result in further pinning action at pellet-clad interfaces, which may also result in accelerated aging of the clad tubing.

The induced curvature of $0.218 \mathrm{~m}^{-1}$ was almost triple that of the perfect bond case and increased $36 \%$ from only pellet-pellet interfaces debonding case. It resulted in small flexural rigidity $29 \mathrm{~N} \cdot \mathrm{m}^{2}$. Compared with the perfect bond case, this flexural rigidity was reduced by up to $62 \%$. The flexural rigidity dropped by $26 \%$ compared with the result for the case with only pellet-pellet interfaces debonded. The curvature and the flexural rigidity indicate that for the interface bonding simulation, the immediate consequence of debonding at the pellet-pellet interface is a significant increase in curvature, which results in a significant reduction in the estimated flexural rigidity. This phenomenon is primarily due to a shift in load-carrying capacity from the pellets to the clad.

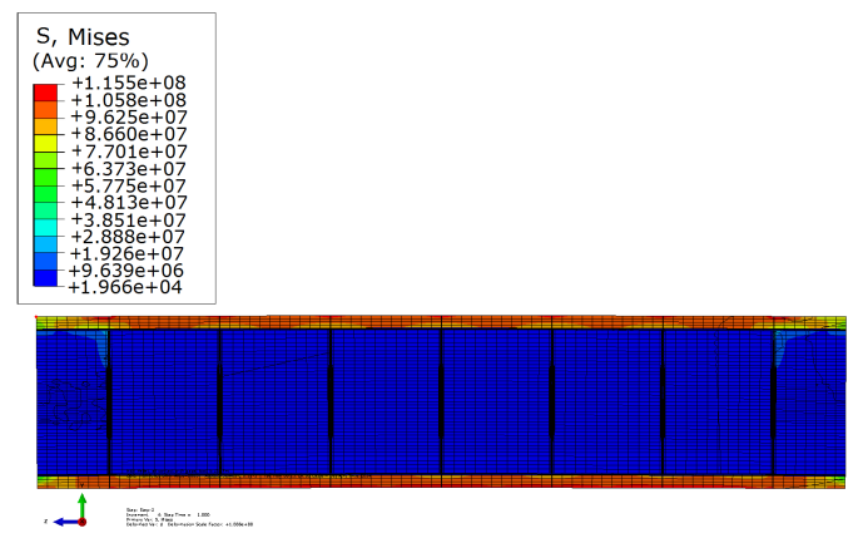

(a) Longitudinal view of resultant von Mises stress

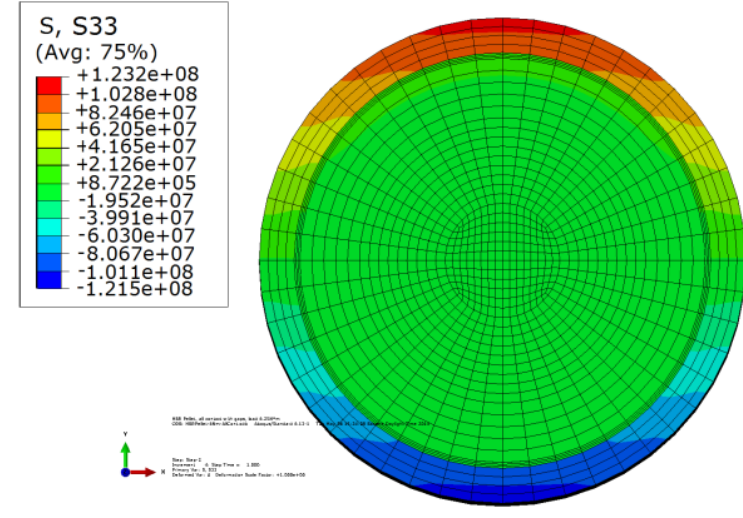

(b) Cross section view of $\sigma_{\mathrm{zz}}$ at a pellet-pellet interface

Figure 10. Normal stress distribution results for $50.8 \mathrm{~mm}$ gauge section model of HBR pellets with empty gaps at debonded pellet-pellet interfaces, and a thin layer at debonded pellet-clad interfaces.

Figure 11 illustrates the shear stress results for this simulation case. The stress pattern appears to be similar to that in the perfect bond case. There were no shear stress concentration inside the gauge section of the cladding as a result of further pellet-clad interface debonding. Because the pellets and the clad can make contact only at the interfaces, the clad cannot directly transfer the shear stress within the gauge section. However, there were some stress concentrations at the boundary as a result of component contact.

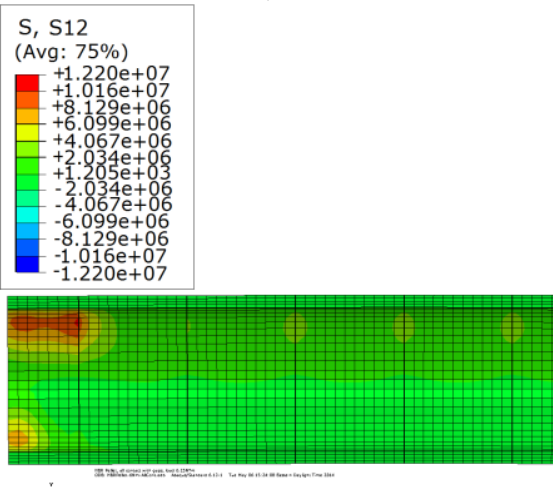

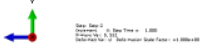

(a) Shear stress $\sigma_{x y}$

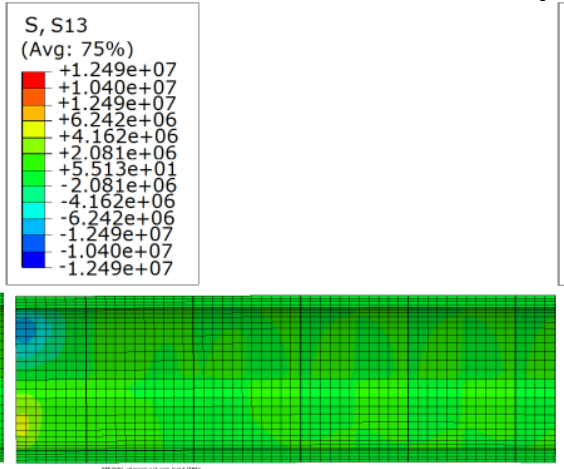

A

(b) Shear stress $\sigma_{\mathrm{xz}}$
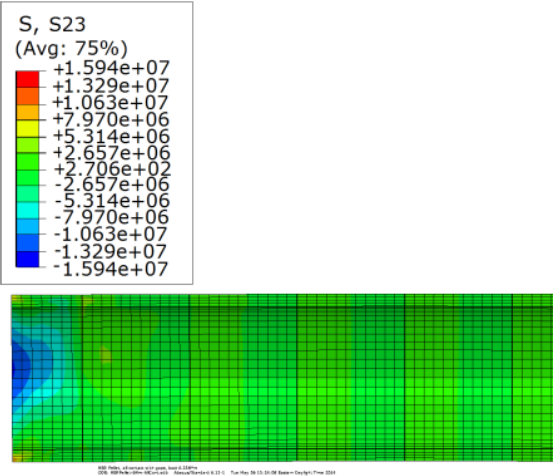

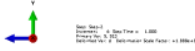

(c) Shear stress $\sigma_{\mathrm{yz}}$ 
Figure 11. Shear stress distribution at the clad of the $50.8 \mathrm{~mm}$ gauge section model of HBR pellets with empty gaps at debonded pellet-pellet interfaces, and a thin layer at debonded pellet-clad interfaces.

\subsection{EFFECT OF GAPS BETWEEN PELLETS}

To study the effects of gaps between pellets on the system response, debonded pellet-pellet interfaces without gaps were modeled. Then the simulation results were compared with those cases with empty gaps between pellets. In these cases, a thin layer with elastic properties of epoxy was tied to the pelletclad interfaces or filled at debonded pellet-clad interfaces to simulate adhesive bonding or radial compressive residual stress. The pellets were all in direct contact with one another without gaps at the pellet-pellet interfaces.

\subsubsection{Debonded pellet-pellet interfaces without gaps}

As illustrated in Figure 12, the normal stress distribution of this case appears to be different from that of the debonded pellet-pellet interface case with empty gaps in Figure 8. The maximum stress occurred at the top of the clad at pellet-pellet interface regions; however, at the compression side, interface stress concentrations occurred at the pellets instead of at the clad. This was because there were no gaps at the pellet-pellet-clad interface region. Thus the contact pellets provided good internal support to the clad tubing structure. Furthermore, the pellets seem to have carried a significant portion of the bending moment resistance via pellet-pellet interaction (pinching at pellet corners), which significantly mitigated the stress level of the clad at the bottom (compression) region. The bending moment on the clad calculated from the resultant $\sigma_{\mathrm{zz}}$ was $3.99 \mathrm{~N} \cdot \mathrm{m}$, which was $30 \%$ lower than the case for debonded pelletpellet interfaces with gaps. The bending moment on pellets was $2.26 \mathrm{~N} \cdot \mathrm{m}$, which was more than four times of the bending moment on pellets for the case with gaps. The results indicates that the pellets without gaps can carry more bending moment resistance than can the pellets with gaps shown in Figure 8 . However, the clad still carried more bending moment than the pellets due to the interface debonding. The pellets and the clad were all under the linear elastic range at the maximum stress level, because of the high yield strength of the pellet and clad material, as well as the small bending load. The pellet stress profiles show asymmetric pattern because of the asymmetric contact between the tension and compression sides at the debonded pellet-pellet interfaces.

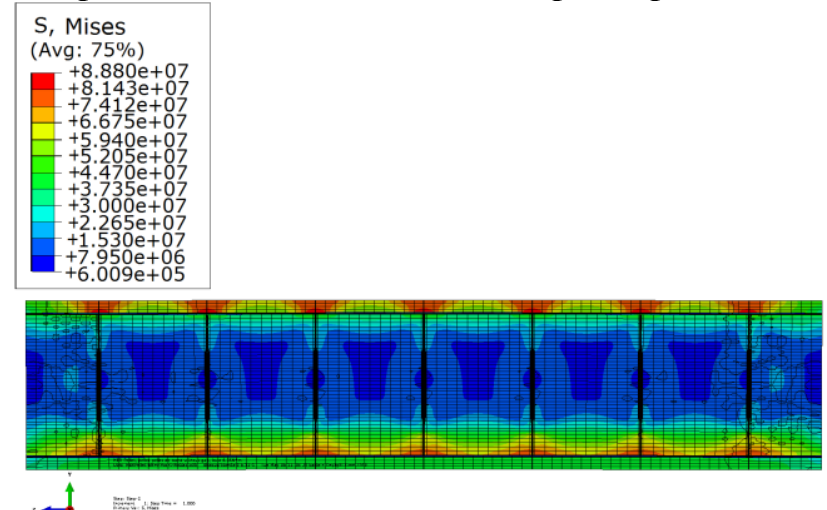

(a) Longitudinal view of resultant curvature and von Mises stress

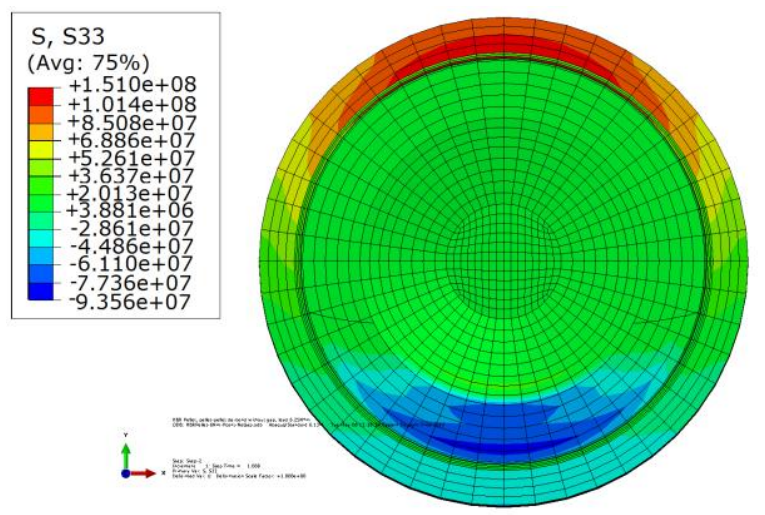

(b) Cross section view of $\sigma_{z z}$ at a pellet-pellet interface

Figure 12. Normal stress distribution results for $50.8 \mathrm{~mm}$ gauge section model of HBR pellets with debonded pellet-pellet interfaces without gaps, and bonded pellet-clad interfaces. 
The direct pellet-pellet contact interaction also provided a significant increase in bending moment resistance; it resulted in a much smaller curvature deformation. In this case, the resultant curvature was $0.119 \mathrm{~m}^{-1}$. The flexural rigidity of the debonded pellet-pellet interfaces case without gaps was $53 \mathrm{~N} \cdot \mathrm{m}^{2}$, which was 1.4 times of that of the case with gaps. Thus, the gaps play an important role in the estimation of flexural rigidity.

Figure 13 shows the shear stress distribution at the clad for this case. The shear stress concentration occurred only at the top tension side, unlike in the case for pellet-pellet interface debonding with small gaps. The maximum stress concentration level was close to the results in Figure 9. At the bottom compression side, the shear stress level was low. The reason is the same as for the normal stress results: when the gaps are eliminated, pellet-to-pellet direct pinning helps lower the stress on the clad at the bottom region interfaces using epoxy.

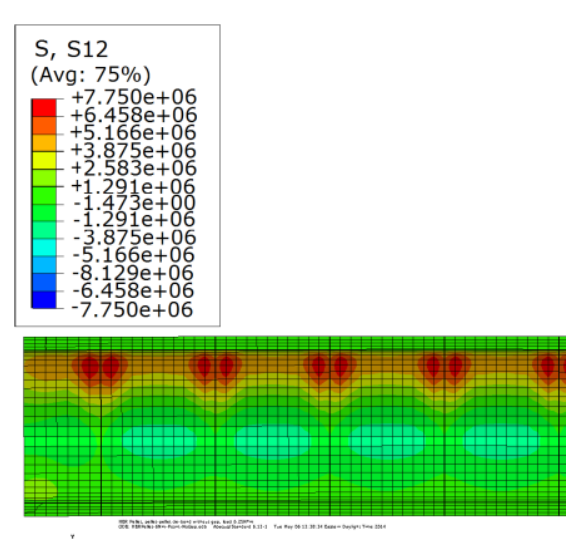

$\stackrel{1}{a}$

(a) Shear stress $\sigma_{x y}$

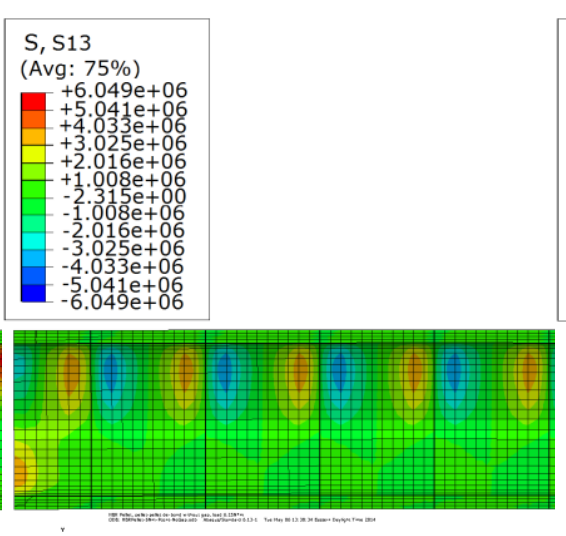

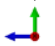

(b) Shear stress $\sigma_{\mathrm{xz}}$

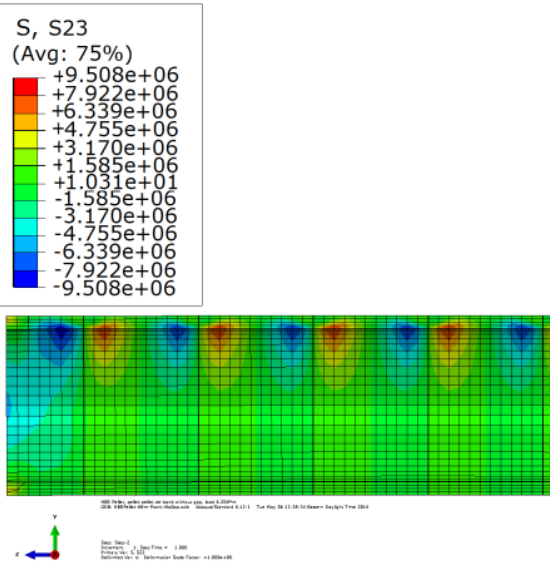

(c) Shear stress $\sigma_{\mathrm{yz}}$

Figure 13. Shear stress distribution at the clad of the $50.8 \mathrm{~mm}$ gauge section model of HBR pellets with debonded pellet-pellet interfaces without gaps, and bonded pellet-clad interfaces.

\subsubsection{Debonded pellet-clad and pellet-pellet interfaces without gaps}

The second simulation case is for debonded pellet-clad interfaces and no gaps at debonded pelletpellet interfaces. Figure 14 illustrates the HBR rod responses to the bending moment in this simulation. The longitudinal cut view shows a stress concentration at the top (tension) region of the $\mathrm{Zr}-4$ clad throughout the gauge section, but the rod did not yield. In the bottom (compression) region, the stress level was low at the clad. The maximum stress still occurred at the compression side of the pellet region where the pellets were pinned to one another. Figure 14 shows similar interfacial results to those observed in Figure 12 for the bonded pellet-clad interfaces and debonded pellet-pellet interfaces without gaps. The pellets carried a large portion of the bending moment resistance via the pinching pellet corners and reduced the stress intensity at the bottom (compression) portion of the clad. The major difference compared with the results shown in Figure 12 is the extensive stress concentration observed at the top region of the clad throughout the entire gauge section, instead of the localized area observed at the interface region in Figure 12. The bending moment distribution was $4.15 \mathrm{~N} \cdot \mathrm{m}$ on the clad and $2.10 \mathrm{~N} \cdot \mathrm{m}$ on pellets, respectively. The clad assumed most of the bending moment resistance, because there was the lack of a direct mechanism for transferring the load from pellet to clad or vice versa due to the debonded pellet-clad interfaces. However, compared to the same interface debonding case with gaps, the bending 
moment on the clad was $33 \%$ lower than that of the case with gaps. The pellets retook a large amount of the bending moment and helped reduce the bending load on the clad.

The resultant curvature was $0.146 \mathrm{~m}^{-1}$ for this case. The estimated flexure rigidity was $43 \mathrm{~N} \cdot \mathrm{m}^{2}$, which was 1.5 times that of the same interface debonding case with gaps. The reason for the large increase in flexural rigidity is the same as discussed in previous section due to pellet-pellet direct contact without gaps. The effect of gaps inside fuel rod system cannot be ignored.

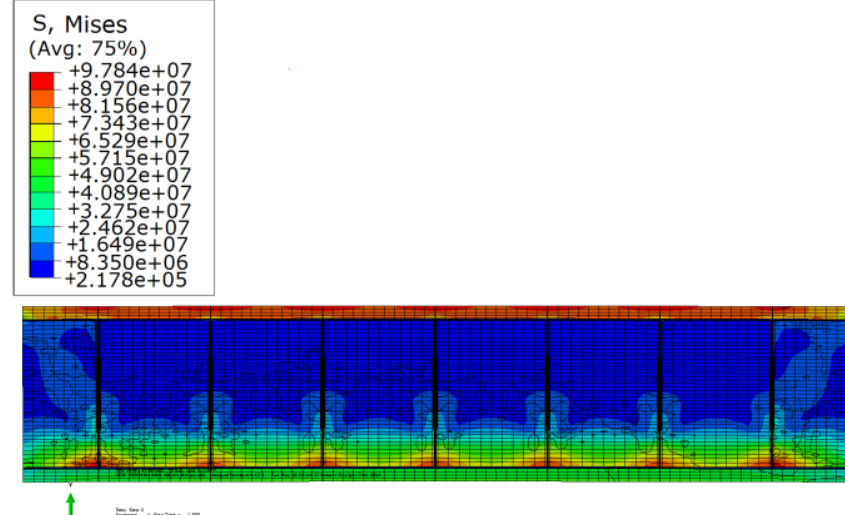

(a) Longitudinal view of curvature and von Mises stress results

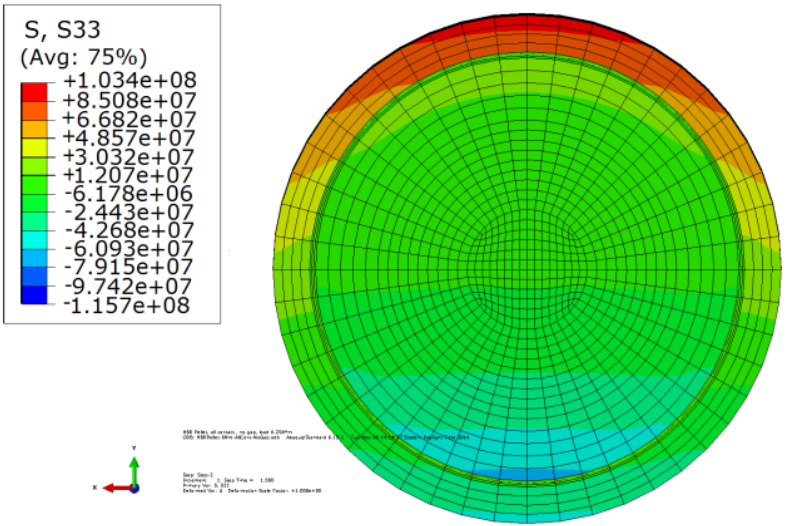

(b) Cross section view of the normal stress, $\sigma_{z z}$, results at a pellet-pellet interface

Figure 14. Normal stress distribution results for the $50.8 \mathrm{~mm}$ gauge section model of HBR pellets without gaps at debonded pellet-pellet interfaces, and with a thin layer at debonded pellet-clad interfaces.

The shear stress in radial direction $\sigma_{x y}$ shows different stress levels at the top tension side and bottom compression side at the clad (Figure 15[a]). Similar to the normal stress distribution, the shear stress at the bottom side of the clad was significantly lowered by pellet-pellet direct pinching at the compression side. The shear stresses $\sigma_{\mathrm{xz}}$ and $\sigma_{\mathrm{yz}}$ showed no stress concentration inside the clad, which appears to be a stress pattern similar to that for interface debonding with gaps. However, the maximum stress levels were lower than the levels for those cases, also, because the pellets assumed a large portion of the bending load when the gaps were eliminated.

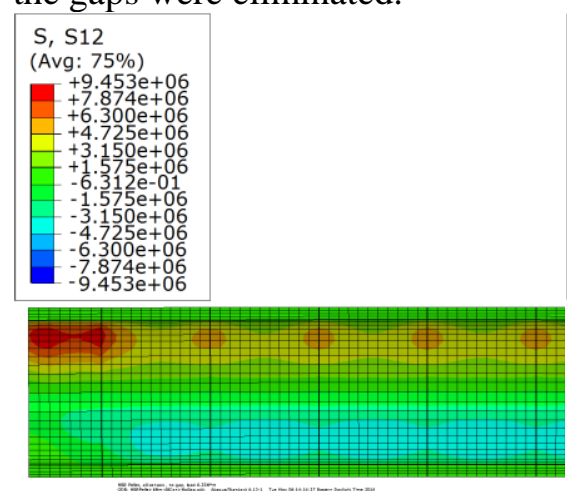

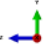
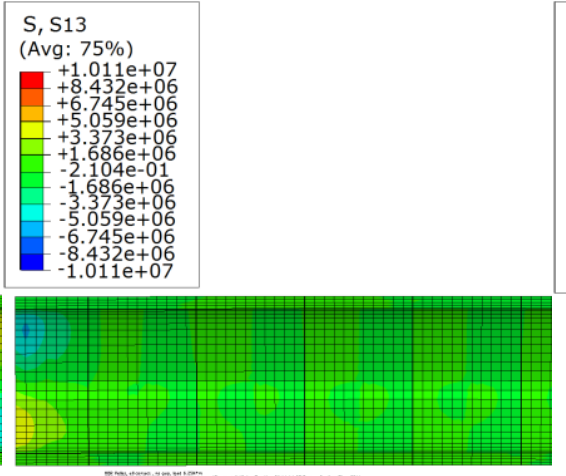

A

(b) Shear stress $\sigma_{\mathrm{xz}}$

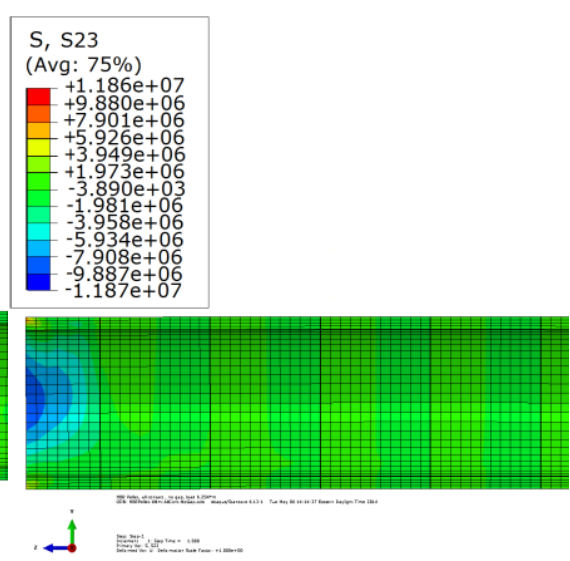

(c) Shear stress $\sigma_{\mathrm{yz}}$

Figure 15. Shear stress distribution and curvature results for the $50.8 \mathrm{~mm}$ gauge section model of HBR pellets without gaps at debonded pellet-pellet interfaces, and with a thin layer at debonded pellet-clad interfaces. 


\section{DISCUSIONS}

\subsection{INTERFACE BONDING EFFICIENCY}

The simulation cases are summarized in Table 2, where the flexural rigidity $E I$ and bending moments distributed among the clad and the fuel are compared case by case. The immediate consequence of interface debonding was a shift in the load-carrying capacity from the fuel to the clad, as well as a reduction in flexural rigidity. Using flexural rigidity as an index, interface bonding efficiency (IBE) can be defined as a parameter to evaluate the interface bonding condition and deficiency. The flexural rigidity of the perfect bond condition was used as baseline, and IBE was defined as,

$\mathrm{IBE}=\mathrm{EI}$ of interface debonded / EI of perfect bond

Thus IBE for the perfect bond condition was defined as $100 \%$ in Table 2 . The flexural rigidity was 77 $\mathrm{N} \cdot \mathrm{m}^{2}$ when the pellets were perfectly bonded with epoxy. Fuel took more bending moment than clad. When there was debonding at the pellet-pellet interfaces with gaps, oppositely, the clad at the pellet-pellet interfaces carried most bending moment; accordingly bending moment on the fuel decreased significantly. The flexural rigidity decreased to $39 \mathrm{~N} \cdot \mathrm{m}^{2}$. So IBE dropped to $51 \%$ in this case. In the case pellet-pellet interface debonded without gaps, the flexural rigidity dropped to $53 \mathrm{~N} \cdot \mathrm{m}^{2}$, which is $26 \%$ higher than the case with gaps, indicating a significant increase in system stiffness. The pellets without gaps can carry more bending moment resistance than can the pellets with gaps. IBE was $69 \%$, which also increased $26 \%$ compared to the same bonding condition with gaps. The gaps at the interfaces of the fuel rod have a significant impact on system structural performance, especially at pellet-pellet interfaces.

Further debonding at the pellet-clad interfaces caused the flexural rigidity to drop further, by $25 \%$ and $19 \%$, respectively, for the cases with gaps and without gaps. Flexural rigidity was reduced more by debonding at pellet-pellet interfaces than by debonding at pellet-clad interfaces. Overall, between the perfect bond and the debond at all interfaces cases, flexural rigidity dropped by about 62 and $44 \%$, respectively, for cases with gaps and without gaps. As results, IBE dropped to 38\% and 56\% for both debonding at pellet-clad and pellet-pellet interfaces respectively, with and without gaps.

Table 2.The flexural rigidity, bending moment and interface bonding efficiency comparison between the different bonding conditions

\begin{tabular}{|c|c|c|c|c|c|c|}
\hline $\begin{array}{l}\text { Interface bonding } \\
\text { conditions }\end{array}$ & $\begin{array}{c}\text { Flexural } \\
\text { rigidity } \\
E I \\
\left(\mathrm{~N} \cdot \mathrm{m}^{2}\right)\end{array}$ & $\begin{array}{c}\text { Interface } \\
\text { bonding } \\
\text { efficiency } \\
(\%)\end{array}$ & $\begin{array}{c}\text { Efficiency } \\
\text { decrease from } \\
\text { only pellet-pellet } \\
\text { debond to further } \\
\text { pellet-clad debond } \\
(\%)\end{array}$ & $\begin{array}{l}\text { Efficiency } \\
\text { increase from } \\
\text { with gaps to } \\
\text { without gaps } \\
(\%)\end{array}$ & $\begin{array}{c}\text { Clad } \\
\text { bending } \\
\text { moment } \\
\text { M } \\
(\mathrm{N} \cdot \mathrm{m})\end{array}$ & $\begin{array}{c}\text { Pellet } \\
\text { bending } \\
\text { moment } \\
\text { M } \\
(\mathrm{N} \cdot \mathrm{m})\end{array}$ \\
\hline $\begin{array}{l}\text { Perfect bond with } \\
\text { epoxy }\end{array}$ & 77 & 100 & & & 2.45 & 3.8 \\
\hline $\begin{array}{l}\text { Pellet-pellet } \\
\text { interface with gap } \\
\text { debond, pellet-clad } \\
\text { interface bonded } \\
\text { with epoxy }\end{array}$ & 39 & 51 & & & 5.73 & 0.52 \\
\hline $\begin{array}{l}\text { Pellet-pellet } \\
\text { interface without } \\
\text { gap debond, pellet- } \\
\text { clad interface } \\
\text { bonded with epoxy }\end{array}$ & 53 & 69 & & 26 & 3.99 & 2.26 \\
\hline
\end{tabular}




\begin{tabular}{|l|c|c|c|c|c|c|}
\hline $\begin{array}{l}\text { Pellet-pellet } \\
\text { interface with gap } \\
\text { debond, pellet-clad } \\
\text { interface debond } \\
\text { with epoxy }\end{array}$ & 29 & 38 & 25 & & 6.23 & 0.02 \\
\hline $\begin{array}{l}\text { Pellet-pellet } \\
\text { interface without } \\
\text { gap debond, pellet- } \\
\text { clad interface } \\
\text { debond with epoxy }\end{array}$ & 43 & 56 & 19 & 32 & 4.15 & 2.10 \\
\hline
\end{tabular}

\subsection{INTERFACE BONDING MATERIAL}

To investigate the impact of the adhesive bonding material, the Young's modulus of the bonding material was set at 10 times the Young's modulus of the epoxy with the material properties shown in Table 1. The similar series of simulations were conducted for the system with this stiffer interface bonding material. Except for the epoxy, all the materials were the same as those used in the previous simulations. The loading and boundary conditions were identical to those used in the previously simulations.

The difference between curvature results for a bonding material with baseline epoxy and 10 times strength of baseline epoxy at the pellet-clad interface can be significant in some cases. As the Young's modulus of the bonding material increased, the curvature decreased by $3-26 \%$ for different interface bonding conditions. The flexural rigidity increased by the same percentage as that of the curvature decreased in the corresponding case.

For all interfaces debonding cases, the flexural rigidities for different interfacial materials were very close; this is due to interface bond functionality was lost in such scenario.

Table 3.The flexural rigidity comparison between the different interface bonding material

\begin{tabular}{|l|c|c|c|}
\hline Interface bonding conditions & $\begin{array}{c}\text { Flexural rigidity EI } \\
\text { for interface } \\
\text { material using } \\
\text { elastic properties of } \\
\text { epoxy } \\
\left(\mathrm{N} \cdot \mathrm{m}^{2}\right)\end{array}$ & $\begin{array}{c}\text { Flexural rigidity EI } \\
\text { for interface material } \\
\text { using 10 times the } \\
\text { Young's modulus of } \\
\text { epoxy } \\
\left(\mathrm{N} \cdot \mathrm{m}^{2}\right)\end{array}$ & $\begin{array}{c}\text { Increase from } \\
\text { interface material } \\
\text { using epoxy to 10 } \\
\text { times the Young's } \\
\text { modulus of epoxy } \\
(\%)\end{array}$ \\
\hline Perfect bond & 77 & 87 & 11 \\
\hline $\begin{array}{l}\text { Pellet-pellet interface with gap debond, } \\
\text { pellet-clad interface bonded }\end{array}$ & 39 & 53 & 26 \\
\hline $\begin{array}{l}\text { Pellet-pellet interface without gap debond, } \\
\text { pellet-clad interface bonded }\end{array}$ & 53 & 65 & 3 \\
\hline $\begin{array}{l}\text { Pellet-pellet interface with gap debond, } \\
\text { pellet-clad interface debonded }\end{array}$ & 29 & 30 & 4 \\
\hline $\begin{array}{l}\text { Pellet-pellet interface without gap debond, } \\
\text { pellet-clad interface debonded }\end{array}$ & 43 & 45 & 4 \\
\hline
\end{tabular}




\subsection{FEA RESULTS BENCHMARKED WITH CIRFT DATA AND FUEL PROPERTY ESTIMATIONS}

The flexural rigidity and bending moment resistance capacity of the fuel rod are strongly dependent on interface bonding conditions at pellet-clad and pellet-pellet interfaces. This discovery was further validated from CIRFT test results performed on HBU HBR SNF pellet-clad system.

The condition of the HBU HBR CIRFT test specimens resembles that of the $50.8 \mathrm{~mm}$ gauge section FEA model where SNF system interface gaps were filled with bonding material. The HBR CIRFT specimen was tested under a $6.25 \mathrm{~N} \cdot \mathrm{m}$ bending moment. Figure 3 shows CIRFT SNF test data. The flexural rigidity based on the CIRFT SNF test data was observed to be between 60 and $70 \mathrm{~N} \cdot \mathrm{m}^{2}$ and the curvature amplitude was near $0.09 \mathrm{~m}^{-1}$. The baseline flexural rigidity of $68 \mathrm{~N} \cdot \mathrm{m}^{2}$ was obtained from static CIRFT test, where the pellet-clad and pellet-pellet interface bonds should maintain intact before bending fatigue cycling start. Thus, the baseline flexural rigidity used to benchmark the FEA simulation result of perfect bonding case. Table 4 compared CIRFT test data with FEA simulation results with five generalized interface bonding conditions. In reality it was much more complex system regarding interface bonding conditions within a HBU SNF specimens. However, this five interface bonding conditions provide boundary for assessing interface bonding conditions during the cycle fatigue test.

Table 4.CIRFT test data of HBR fuel rod benchmarked with FEA simulation results.

\begin{tabular}{|l|c|c|c|}
\hline $\begin{array}{l}\text { Interface bonding conditions } \\
\text { in FEA }\end{array}$ & $\begin{array}{c}\text { FEA Flexural rigidity } \\
\text { EI for interface } \\
\text { material using elastic } \\
\text { properties of epoxy } \\
\text { (N·m2) }\end{array}$ & $\begin{array}{c}\text { FEA Flexural rigidity EI } \\
\text { for interface material using } \\
\text { 10 times the Young's } \\
\text { modulus of epoxy } \\
\left(\mathrm{N} \cdot \mathrm{m}^{2}\right)\end{array}$ & $\begin{array}{c}\text { CIRFT test } \\
\text { Flexural rigidity } \\
E I\left(\mathrm{~N} \cdot \mathrm{m}^{2}\right)\end{array}$ \\
\hline Perfect bond & 77 & 87 & $\begin{array}{c}68 \\
\text { (baseline) }\end{array}$ \\
\hline $\begin{array}{l}\text { Pellet-pellet interface with } \\
\text { gap debond, pellet-clad } \\
\text { interface bonded }\end{array}$ & 39 & 53 & \begin{tabular}{c}
60 \\
\hline $\begin{array}{l}\text { Pellet-pellet interface } \\
\text { without gap debond, pellet- } \\
\text { clad interface bonded }\end{array}$
\end{tabular} \\
\hline $\begin{array}{l}\text { Pellet-pellet interface with } \\
\text { gap debond, pellet-clad } \\
\text { interface debond }\end{array}$ & 53 & 30 & $\begin{array}{c}\text { (Debonded after } \\
\text { first fatigue } \\
\text { cyclic loading) }\end{array}$ \\
\hline $\begin{array}{l}\text { Pellet-pellet interface } \\
\text { without gap debond, pellet- } \\
\text { clad interface debond }\end{array}$ & 29 & 45 & \\
\hline
\end{tabular}

The baseline flexural rigidity of HBR CIRFT test data was lower than $77 \mathrm{~N} \cdot \mathrm{m}^{2}$ estimated from the FEA. The primary reason is that the virgin or fresh fuel property was used in FEA simulation instead of HBU aging fuel property, and fuel cracking density induced bonding deficiency. Furthermore, under cyclic loading, it was expected that the interface bonding strength can be degraded accordingly, as demonstrated in Figure 3, with decreased flexural rigidity under increased loading cycles. After first fatigue cycle, the flexural rigidity was stable at around $60 \mathrm{~N} \cdot \mathrm{m}^{2}$, which decreased $12 \%$ from baseline data. In addition to interface bonding efficiency, fuel cracking can have further impact on SNF system flexural rigidity representation. To simplify the evaluation of HBU SNF system flexural rigidity, the imperfection 
associated with interface bond or fuel cracking were assigned to the HBU aging fuel and written as

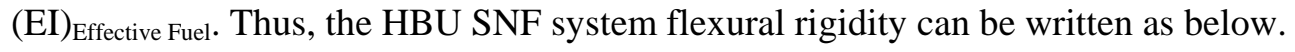

$$
\mathrm{EI}_{\text {system }}=(\mathrm{EI})_{\text {Clad }}+(\mathrm{EI})_{\text {Effective Fuel }}
$$

Thus, the effective fuel flexural rigidity takes into considerations of fuel property degradation due to cracking, interface bonding deficiency implicitly. Based on this simplified rule, the effective Yong's module of the HBU fuel can be quantified, as shown in Table 5. In baseline/good bond condition, effective fuel property dropped $38 \%$ compared to fresh fuel property. After first fatigue cycle, effective fuel property further degraded to 50\% due to combined effect of HBU fuel and interface bonding deficiency induced by cyclic loading at pellet-pellet interface.

Table 5. Effective fuel property estimation from testing data with consideration of interface bonding efficiency

\begin{tabular}{|l|c|c|c|c|c|}
\hline $\begin{array}{l}\text { Interface } \\
\text { bonding } \\
\text { condition }\end{array}$ & $\begin{array}{c}\text { Tested } \\
\text { flexural } \\
\text { rigidity EI } \\
\left(\mathrm{N} \cdot \mathrm{m}^{2}\right)\end{array}$ & $\begin{array}{c}\text { Clad } \\
\text { flexural } \\
\text { rigidity EI } \\
\left(\mathrm{N} \cdot \mathrm{m}^{2}\right)\end{array}$ & $\begin{array}{c}\text { Effective } \\
\text { Fuel flexural } \\
\text { rigidity EI } \\
\left(\mathrm{N} \cdot \mathrm{m}^{2}\right)\end{array}$ & $\begin{array}{c}\text { Effective } \\
\text { Fuel young's } \\
\text { modulus E } \\
(\mathrm{GPa})\end{array}$ & $\begin{array}{c}\text { Effective Fuel young's } \\
\text { modulus E degraded from } \\
\text { original E in Table 1 } \\
(\%)\end{array}$ \\
\hline Baseline & 68 & 28 & 40 & 125 & 38 \\
\hline $\begin{array}{l}\text { Debonded after } \\
\text { first fatigue } \\
\text { cyclic loading }\end{array}$ & 60 & 28 & 32 & 100 & 50 \\
\hline
\end{tabular}

\section{CONCLUSION}

Based on FEA simulation results and further verification from ORNL HBR SNF rod bending test results, the impacts of interfacial bonding efficiency at pellet-pellet and pellet-clad interfaces on the HBR rod system performance can be summarized as below.

FEA simulations provided fundamental understanding of interface bonding efficiency for HBU SNF composite rod system. The immediate consequence of interface debonding was a shift of bending moment resistance capacity from the fuel to the clad, as well as reduction in SNF system flexural rigidity. The gaps at the interfaces of the fuel rod also have a significant impact on SNF system structural performance. FEA successfully translated the global moment-curve response to the local stress-strain profile. FEA results show the various stress distribution trends on the SNF system under different interface bonding conditions, which can be used to study pellet-clad interaction effect.

FEA helps to quantify interface bonding efficiency and evaluate potential impact of interface debonding. Using the flexural rigidity of perfect bond as baseline, interface bonding efficiency decreased corresponding to the interface debonding. When the interface material's stiffness was increased, the HBU SNF system stiffness increased accordingly. The developed simplified rule of the effective fuel flexural rigidity with the consideration of HBU aging fuel and SNF system interface bonding efficiency was used to estimate the fuel Young's modulus of the tested HBU SNF. Due to the end dish-in of the SNF pellet, the pellet-pellet has limited end contact surface and would be easily debonded under cyclic bending loading, Based on HBU HBR SNF CIRFT test, after first fatigue cycle, the effective Young's modulus of HBU fuel is was reduced to half of that of the fresh fuel.

Future works will be extended further on detailed fuel property study, including consideration of cracking of pellets and aging material properties to assess more realistic fuel behavior. Anisotropic material behavior of cladding material $\mathrm{Zr}-4$ and clad aging will also be evaluated to estimate its impact on bending deformation simulation. Finally, interfacial bonding efficiency need to be further studied with regarding material properties, where oxide layer on the clad surface will also be considered in the model system. 


\section{ACKNOWLEDGMENTS}

This research was sponsored by DOE UFDC and was conducted at Oak Ridge National Laboratory under contract DE-AC05-00OR22725 with UT-Battelle, LLC. The authors would like to thank Program Managers Bruce Bevard and Rob Howard for providing guidance and support to this project; and Edgar Lara-Curzio for reviewing this article.

\section{REFERENCES}

1. US Department of Energy, Used Fuel Disposition Campaign, Used Nuclear Fuel Loading and Structural Performance Under Normal Conditions of Transport-Modeling, Simulation and Experimental Integration RD\&D Plan, FCRD-UFD-2013-000135, Department of Energy, Washington, D. C., April 1, 2013.

2. H. Wang, J.-A.J. Wang, T. Tan, H. Jiang, T. Cox, R. Howard, B. Bevard, and M. Flanagan, Development of U-frame Bending System for Studying the Vibration Integrity of Spent Nuclear Fuel, Journal of Nuclear Material, 440, 201-13, 2013.

3. J.-A.J. Wang, H. Wang, H. Jiang, B. Bevard, and R. Howard, CIRFT Testing Results on High Burnup UNF, M2-FCRD-UFD-2014-000053, Oak Ridge National Laboratory, Oak Ridge, Tennessee, September 2014.

4. J.-A.J. Wang, H. Wang, Mechanical Fatigue Testing of High Burnup Fuel for Transportation Applications, NUREG/CR-7198, May 2015.

5. H. Stehle, H. Assmann and F. Wunderlich, Uranium Dioxide Properties for LWR Fuel Rods, Nuclear Engineering and Design, 33, 230-260,1975

6. K. C. Radford, Effect of Fabrication Parameters and Microstructure on the Mechanical Strength of $\mathrm{UO}_{2}$ Fuel Pellets. Journal of Nuclear Material, 84, 222-236, 1979

7. B. Michel, J. Sercombe and G. Thouvenin, A New Phenomenological Criterion for Pellet-Cladding Interaction Rupture, Nuclear Engineering and Design, 238, 1612-1628, 2008

8. B. Michel, J. Sercombe, G. Thouvenin, and R. Chatelet, 3D Fuel Cracking Modelling in Pellet Cladding Mechanical Interaction, Engineering Fracture Mechanics

9. BARC Highlights, Nuclear Fuel Cycle, Chapter 4, Bhabha Atomic Research Center, Trombay,Mumbai, India, 2007, pp. 35-39. http://www.barc.ernet.in/publications/eb/golden/nfc/toc/Chapter\%204/4.6.pdf

10. K. J. Geelhood et al., PNNL Stress/Strain Correlation for Zircaloy, PNNL-17700, Pacific Northwest National Laboratory, Richland, Washington, July 2008.

11. N. Marchal, C. Campos and C. Garnier, Finite Element Simulation of Pellet-Cladding Interaction (PCI) in Nuclear Fuel Rods, Computational Material Science, 45, 821-826,2009

12. J.-A.J. Wang, H. Jiang, B. Bevard, J. Scaglione, Quantification of CIRFT System Biases and Uncertainties Associated When Testing High Burnup Spent Nuclear Fuel,FCRD-UFD-2014-000604, Oak Ridge National Laboratory, Oak Ridge, Tennessee, September 2014.

13. J.-A.J. Wang, H. Jiang, and H. Wang, Using Finite Model Analysis and Out of Hot Cell Surrogate Rod Testing to Analyze High Burnup Used Nuclear Fuel Mechanical Properties, ORNL/LTR2014/257, Oak Ridge National Laboratory, Oak Ridge, Tennessee, August 2014. 